\title{
MECANISMOS DE COMBATE À CRIMINALIDADE TRANSNACIONAL: UMA PERCEPÇÃO DE ANOMIA NO ÂMBITO INTERNACIONAL QUANTO AOS CRIMES AMBIENTAIS
}

\section{Claudia Ribas Marinho ${ }^{1}$}

\section{Resumo:}

A Globalização fez emergir a criminalidade organizada transnacional que se favorece da visão tradicionalista do direito penal, limitada ao princípio da territorialidade e da soberania estatal. A repressão criminal, até então circunscrita aos limites territoriais estatais, não é suficiente para o embate à esse tipo criminalidade o que obrigou os Estados a uniram-se para a aprovação de tratados internacionais para a cooperação jurídica internacional no combate de crimes com tráfico de entorpecentes, armas e pessoas, corrupção e lavagem de dinheiro. Contudo, não há idêntica preocupação nos esforços para a uma colaboração no enfrentamento da criminalidade ambiental transfronteiriça.

Palavras-chave: Criminalidade Transnacional; Cooperação Jurídica Internacional; Lavagem De Dinheiro; Tráfico De Drogas; Crimes Ambientais

\section{MECHANISMS TO FIGHT TRANSNATIONAL CRIME: A PERCEPTION OF ANOMIE AT THE INTERNATIONAL LEVEL REGARDING ENVIRONMENTAL CRIMES}

\begin{abstract}
:
Globalization has given rise to transnational organized crime which favors the traditionalist view of criminal law, limited to the principle of territoriality and state sovereignty. Criminal repression, hitherto limited to state territorial limits, is not sufficient to combat this type of crime, which has forced states to unite for the approval of international treaties for international legal cooperation in the fight against drug trafficking crimes., weapons and people, corruption and money laundering. However, there is no similar concern in efforts to collaborate in tackling transboundary environmental crime.
\end{abstract}

Keywords: Transnational Crime; International Legal Cooperation; Money Laundry; Drug Trafficking; Environmental Crimes

\section{INTRODUÇÃO}

\footnotetext{
${ }^{1}$ Doutoranda em Ciência Jurídica pela Universidade do Vale do Itajaí/SC - UNIVALI, na linha de pesquisa Direito Ambiental, Transnacionalidade e Sustentabilidade. Graduada em Direito pela Universidade Federal de Santa Catarina (1999) e Administração de Empresas pela ESAG/UDESC (1998). Especialista em Direitos Humanos pela UDESC (2001) e em Direito e Gestão Judiciária pela Academia Judicial/TJSC (2009). Mestre em Ciência Jurídica na Univali (SC) e Derecho Ambiental y de la Sostenibilidad pela Universidad de Alicante, Espanha (2015). Juíza de Direito na Vara de Execuções Penais de Itajaí, TJSC. E-mail: claudiaribasmarinho@gmail.com
} 
A Globalização é um fenômeno econômico, social, cultural e político que se caracteriza por um encurtamento das distâncias territoriais, com facilitação da comunicação, aproximando as nações de todo o mundo. Observa-se nesse processo uma integração de mercados, o desenvolvimento de sistemas de transportes e das tecnologias de comunicação, e expansão dos mercados econômicos.

As fronteiras físicas deixaram de ser limites para a expansão econômica, a aproximação de sociedades, eclosão de empresas atuando nos mais diversos ramos e países.

Nesse cenário emerge o processo que passou a ser denominado de transnacionalização, que nas palavras da autora brasileira Joana Stelzer é "evidenciada pela desterritorialização dos relacionamentos político-sociais” (STELZER, 2011. p.16).

Contudo, essa facilidade de deslocamento, comunicação e relações internacionais fez emergir a criminalidade organizada transnacional, que se favorece da visão tradicionalista do direito penal, enquanto que o Estado continuou limitado na sua atuação puniendi por conta do princípio da territorialidade e da soberania estatal.

A repressão criminal, até então circunscrita aos limites territoriais estatais, não é suficiente para o embate a criminalidade organizada e com atuação transnacional. Os mecanismos jurisdicionais estatais não são capazes de individualmente e solitariamente efetivar um controle da criminalidade que segue um paradigma diverso do que se via até há algumas décadas.

Por conta disso, desde a década de 80 do século passado os Estados passaram a reconhecer a existência de uma criminalidade organizada transnacional, e a necessidade de uma união e cooperação internacional mútua para o seu combate. Através da edição de tratados, os países signatários identificaram a prática do tráfico de drogas internacional, do tráfico de pessoas e armas, a corrupção e a lavagem de dinheiro, comprometendo-se a estabelecer práticas internas para facilitar a investigação e punição dessas práticas, numa criação de uma rede de cooperação jurídica internacional.

Contudo, não se vê a mesma preocupação de criação de redes e imposições aos Estados para que unam esforços quando a prática criminosa transnacional tem por objeto o meio ambiente, ou seja, quando a degradação ambiental dolosamente praticada especialmente pelos entes coletivos - causam danos de efeitos transfronteiriços. Embora a partir da Rio 92 tenha se exigido que os Estados se obriguem de diversas formas na proteção 
ambiental, ainda se baliza a proteção ambiental no âmbito nacional, especialmente no que se diz respeito a punição pela prática de crime, já que fundada na criminologia tradicional que entre outros, ainda se limita ao princípio da territorialidade e o respeito à soberania dos Estados na investigação e processamento da ação penal, sem qualquer preocupação com eventual colaboração entre os entes interessados.

O presente artigo foi elaborado a partir de revisão bibliográfica, e se divide em 5 capítulos. No primeiro enveredou-se por uma das fontes mais democráticas do direito internacional - o tratado - e a sua utilização pelos Estados signatários para criarem uma cooperação jurídica internacional. Nos capítulos 2, 3 e 4 destacou-se o reconhecimento internacional da criminalidade internacional organizada, especialmente através do tráfico de drogas, com a aprovação da Convenção Contra o Tráfico Ilícito de Entorpecentes e Substâncias Psicotrópicas, e em seguida, da Convenção de Palermo e as ações internacionais para suprimir o tráfico de pessoas, mulheres e crianças, bem como de armas; além de ser analisada a Convenção de Mérida que se preocupou com a prática de corrupção em que se observou a evolução dos mecanismos de cooperação internacional para coibir a prática de lavagem de dinheiro como forma de impedir a ocorrência dos demais crimes. No último capítulo foram feitas considerações a respeito da anomia no âmbito internacional quanto a criação de uma cooperação jurídica entre as nações para evitar o cometimento de crimes ambientais transnacionais.

Finalmente, as considerações finais têm por finalidade a síntese das ideias levantadas no artigo, visando ao aprimoramento do assunto abordado e à contribuição à produção científica no estudo da criminalidade transnacional organizada no cenário de globalização. No desenvolvimento do artigo foi empregado o método indutivo, pesquisando e identificando as partes do problema para chegar-se às considerações finais, sob as técnicas da pesquisa bibliográfica e do fichamento.

\section{Cooperação Jurídica Internacional.}

Até recentemente o mundo se viu alicerçado em uma tradição jurídica fundada no monismo jurídico, em que estabelece a exclusividade da produção normativa ao Estado, que tem obrigatoriedade e vigência apenas em seu território. Marcio Ricardo Staffen afirma que "via de regra, o confinamento do fenômeno jurídico ao contexto territorial com exclusividade 
é produto do Estado Moderno, estruturado a partir dos Tratados de Paz da Vestfália, instituição cujos fundamentos e atribuições ainda estão presentes na atualidade" (STAFFEN, 2018, p.11)

A respeito da exclusividade estatal na produção jurídica, os Professores Paulo Cruz e Maurizio Oliviero (2013, p. 33) contribuem afirmando que:

Durante toda a fase seguinte à Paz da Westfalia (ou seja, durante as duas fases da modernidade) o direito foi progressivamente visto como um aparato tipicamente estatal, fruto exclusivo do monopólio da força sobre a qual a soberania encontrava fundamento. Na medida em que a ratio do direito consistia em "projetar" os comportamentos dos consorciados, era evidente o papel fundamental que isto representava enquanto instrumento de governo de um modelo (quase sempre constitucionalizado) de "vida social" no qual as relações interindividuais não podiam prescindir das fronteiras do Estado.

Marcelo Varella lembra que a soberania no sentido clássico, aquele concebido por Grotius ou Hobbes, tem um evidente enfraquecimento, à medida que assuntos de natureza antes exclusivamente nacionais são resolvidos pelo direito internacional, que tem uma essência volátil. (VARELLA, 2018. p.39)

O recente cenário de globalização permitiu uma maior aproximação das nações, havendo a necessidade de que estas se unissem para construírem uma ordenação normativa de assuntos de interesse comum, com abdicação - ainda que voluntária - de parte da soberania. A forma que os Estados têm de obrigaram-se entre si é o tratado², que "nasce a partir da manifestação de vontade de um sujeito de direito internacional (Estado ou Organização Internacional) em regular juridicamente determinada situação no âmbito internacional" (VARELLA, 2018, p. 47), e por isso é a fonte do direito internacional mais democrática, já que a sua incidência é apenas sobre aqueles sujeitos de direito que o firmaram. O prof. Marcelo Varella ensina que "o direito internacional é construído sobre a noção fundamental do consentimento dos Estados. Os Estados ou Organizações Internacionais não são obrigados

2 "Tratado é um acordo internacional concluído por escrito entre Estados ou entre Estados e Organizações Internacionais, regido pelo Direito Internacional, quer conste de um instrumento único, quer de dois ou mais instrumentos conexos, qualquer que seja sua denominação específica". (VARELLA, 2018, p. 37) 
a assinar ou ratificar os tratados. Eles o fazem como manifestação do seu poder soberano" (VARELLA, 2018, p. 37), assim é que a participação numa cooperação jurídica internacional é voluntária.

O autor relembra que "nenhum Estado é forçado a adotar uma norma internacional ou participar de um processo de expansão de direito internacional, cedendo seus espaços de competência interna." (VARELLA, 2018, p. 38). Por outro lado, é certo que se de uma formao não se obriga os estados a adotarem ou firmaram um tratado internacional, por outra, sendo ele signatário sofre consequências em caso de descumprimento.

É que "os Estados estão constantemente submetidos a um conjunto de escolhas, a respeito das quais, para poder obter alguns benefícios jurídicos, políticos, econômicos, ambientais e outros, precisam ceder, cooperar, participar de uma regulação jurídica e política progressivamente mais internacionalizada" (VARELLA, 2018, p. 38).

Por conta dessa necessidade, foi desenvolvido um sistema de auxílio entre as nações e essa cooperação se dá tanto na forma de transferência de conhecimento e técnicas de investigação, como através de auxílio formal previsto nos tratados e acordos ou com base no princípio da reciprocidade. A esse processo se dá o nome de cooperação jurídica internacional que é a "colaboração entre Estados ou entre Estados e tribunais internacionais para a adoção de medidas que contribuam para a consecução de um objetivo comum com reflexos jurídicos” (MESSA, 2014), e é regida pelos seguintes princípios: cooperação dos povos, reciprocidade, competência, especialidade e dupla incriminação (MESSA, 2014).

A partir desses tratados internacionais que visam o combate ao crime organizado, foram criadas várias redes de cooperação internacional e o Brasil faz parte de vários deles: Rede Ibero-Aericana de Cooperação Judicial (IberRED), Rede de Cooperação Jurídica e Judiciária Internacional de Países de Língua Portuguesa (Rede Judiciária da CPLP), Rede Hemisférica de Intercambio de Informações para o Auxílio Jurídico Mútuo em Matéria Penal e Extradição; Rede Ibero-americana de Informação e Documentação Judicial (IberIUS), Rede Ibero Americana de Escolas Judiciais (RIAEJ) e Rede de Poderes Judiciários das Nações SulAmericanas (UNASUL). (MESSA, 2014).

É assim que é possível um auxílio mútuo entre nações para o cumprimento de diversos atos e medidas processuais necessários tanto à investigação como ao processamento de uma ação penal, podendo ser atos de comunicação processual como citações, intimações e notificação, obtenção de provas diversas, compartilhamento de provas, medidas cautelares 
sobre bens (bloqueio, perdimento e repatriação de ativos), além da possibilidade de transferência de processos criminais e de execução de pena (Lei 13.445/2017).

Para fins deste artigo, serão considerados sinônimas as palavras Tratados e Convenções, podendo os documentos indistintamente serem chamados por um ou outro.

\section{Criminalidade transnacional. Convenção Contra o Tráfico Ilícito de Entorpecentes e Substâncias Psicotrópicas}

$\mathrm{Na}$ década de 80 do século passado pode-se dizer que o mundo se aturdiu com pratica de tráfico de drogas de forma organizada e internacional. $\mathrm{O}$ narcotráfico em alta escala teve seu auge nesta década de 80, quando iniciou-se o delineamento do processo de globalização e reconhecimento do fenômeno da Transnacionalidade, quando as fronteiras físicas passaram a ser meras ficções internacionais. A fragilidade da soberania estatal e da utilização do território como seu elemento essencial permitiu uma impunidade quanto aos crimes cujos passos e efeitos transcendem a territorialidade e fronteiras das nações.

Muitos países estavam com a sua imagem diretamente ligada à prática desse crime, com grande injeção do dinheiro vindo do tráfico internacional, que afetava negativamente as estruturas de Estado. A Colômbia é um desses países identificados como um dos berços de grandes organizações do narcotráfico que tinha como destinatário principal os EUA.

Essa atividade criminosa também favoreceu o sistema financeiro mundial, já que o produto desse crime é enviado para os bancos de vários lugares do mundo, especialmente com a intenção de fazer o branqueamento desses valores.

Foi então que os países viram a necessidade de um planejamento conjunto e organização para o combate a essa criminalidade mais organizada e que ultrapassava as fronteiras físicas - meras ficções jurídicas criadas pelos Estados - com habilidades não só de capilarizar a distribuição da droga, mas também de dissimular o recebimento dos valores através da lavagem de dinheiro.

O mundo se deu conta da necessidade de criação de mecanismos de cooperação para combater o crime organizado transnacional, entendendo que a responsabilidade não era exclusiva de apenas um Estado ou dele apenas em seu território, sendo imperiosa a união nos 
esforços para uma resposta penal eficiente. Até mesmo no âmbito dos blocos econômicos regionais houve um reconhecimento de que "um sistema jurisdicional ágil, preciso e de fácil acesso para os interessados certamente é um dos principais elementos que determinam o êxito ou o fracasso de um processo de integração regional. (MOURA, 2014, p. 203)

Assim é que os Estados-Membros da ONU, com o objetivo de reforçar ações para o combate ao tráfico de drogas, assinaram a Convenção das Nações Unidas contra o Tráfico Ilícito de Entorpecentes e Substâncias Psicotrópicas.

“A Convenção de 1988 tem como objetivo promover a cooperação entre os Estados para tratar de forma mais eficaz o tráfico de drogas, acabar com os lucros de organizações criminosas através da produção de drogas ilicitas e do tráfico e fornecer novas ferramentas aos governos. A Convenção também buscou reduzir o sofrimento humano e pediu que os Estados adotassem medidas efetivas na prevenção, tratamento e reabilitação.(ONU, 2019)

Observe-se que a citação acima se utiliza do termo "pediu" como se fosse apenas uma orientação ou simples solicitação feita aos estados signatários, que não teriam qualquer obrigação no cumprimento. Todavia o eventual descumprimento ou não adoção das orientações poderá impor uma série de sanções das mais diversas aos países signatários, especialmente econômicas, havendo também grande pressão social aos governantes para seu cumprimento.

A justificativa para a aprovação da Convenção Contra o Tráfico Ilícito de Entorpecentes e Substâncias Psicotrópicas demonstra a preocupação que as nações tinham com o crescimento exagerado e organização das atividades criminosas com o fim de produção, demanda e tráfico ilícito de entorpecentes, não se limitando a regiões específicas, mas com efeitos transfronteiriços. A inquietação se propaga especialmente quanto aos efeitos nefastos de tal prática criminosa, que tem impactos nocivos à saúde humana e também através de uso de crianças e adolescentes, tanto como consumidores ou como instrumentos do tráfico.

Há um reconhecimento expresso de que essas atividades causam prejuízos econômicos e afetam a segurança e soberania dos Estados. A Convenção utiliza-se da expressão "transnacional" para referir-se a essas atividades criminosas, que procuram 
“invadir, contaminar e corromper as estruturas da administração pública, as atividades comerciais e financeiras lícitas e a sociedade em todos os seus níveis" (BRASIL, 1991).

Nessa Convenção há uma recomendação para que os Estados caracterizem os delitos penais de tráfico de entorpecentes quando cometidos internacionalmente, indicando os tipos penais que devem ser internalizados pela legislação dos países signatários.

No Brasil, a Convenção foi incluída no nosso ordenamento através do Decreto 154/1991 e foi pioneira em todo mundo no compromisso dos países pactuantes de estabelecerem uma cooperação na investigação e práticas de responsabilidade penal quanto a esses delitos. Na mesma oportunidade os signatários acordaram em aprovar no âmbito interno normas que incriminassem e combatessem a prática de lavagem de dinheiro quando o crime antecedente fosse de tráfico ilícito de entorpecentes.

A referida Convenção estabeleceu, ainda, diretrizes sobre cooperação internacional no combate ao tráfico de drogas, dispondo que os delitos não serão considerados fiscais ou políticos, nem delitos politicamente motivados, com o objetivo de dinamizar investigações judiciais. A mesma ainda dispôs que serão considerados passíveis de extradição os delitos nela previstos (art. $6^{\circ}, \S 2^{\circ}$ ) e que, caso um EstadoParte receba pedido de extradição de outro signatário, com o qual não tenha tratado de extradição, poderá considerar a Convenção como base jurídica para sua concessão, com referência àqueles delitos. (PEREIRA, 2016, p. 51)

Assim, há uma consolidação da ideia de cooperação jurídica internacional direcionada ao combate do crime organizado transnacional. Os Estados se comprometem a uma série de atividades e ações de cooperação entre eles. A Convenção estabelece qual a forma de tipificação criminal e ações investigatórias e cautelares que poderão ser realizadas através desta cooperação, como medidas de busca e apreensão, extradição, entre outras.

Os Estados-Partes deverão também adotar medidas para que suas autoridades tenham condições de identificar, detectar e decretar a apreensão desses bens, com o objetivo de realizar eventual confisco, bem como deverão facultar a seus juízes a decretação da apreensão ou o confisco de documentos bancários, financeiros ou comerciais, sem que haja possibilidade de se invocar o sigilo bancário com o intuito de se furtar a 
aplicação da regra. O sigilo bancário não deve, portanto, ser considerado óbice nas investigações penais no âmbito da cooperação internacional. (PEREIRA, 2016, p. 52)

Por conta da edição desta Convenção, foi criado em 1989 o Grupo de Ação Financeira Internacional (GAFI) - Financial Action Task Force - FAFTF - que é um organismo intergovernamental, que iniciou com 7 países, e atualmente fazem parte dele mais de 40. O GAFI editou 40 recomendações aos países signatários ou não com o fim de combater a lavagem de dinheiro e as ações financeiras criminosas. Essas recomendações têm naturezas diversas e procuram padronizar os mecanismos de investigação e combate ao crime organizado, determinando orientações quanto a tipificação dos crimes e sua responsabilização, além de possibilitar ações de extradição, busca e apreensão, intimações, citações e outros atos de investigação e jurisdicionais. Embora essas recomendações não tenham caráter obrigatório, não se limitam apenas sugestões ou conselhos. É que seu descumprimento pode ensejar sanções econômicas até mesmo àqueles que não fazem parte do grupo, e por conta disso "há grande discussão doutrinária quanto à natureza das recomendações do GAFI, se seriam soft law ou hard law, bem como quanto a sua legitimidade de atingir países não membros".(PEREIRA, 2016, p. 53) ${ }^{3}$

Entre as recomendações podemos citar: que a responsabilidade criminal das pessoas coletivas não excluam a responsabilidade das pessoas físicas envolvidas; ações de prevenção a lavagem de dinheiro e utilização das pessoas jurídicas para a prática criminosa; assegurar a responsabilização criminal e, quando ela não seja possível, a responsabilidade civil ou administrativa; ações de investigação e acautelamento como declaração de perdimento e busca e apreensão de bens; além de várias outras medidas determinadas às instituições financeiras para combate à lavagem de dinheiro.

\footnotetext{
3 "O termo soft law surge pela primeira vez, em 1973, em debate capitaneado por René Jean Dupuy na "Hague Academy of the Protection of the Environment and International Law", em Haia, cujo objeto estava circunscrito à criação de fontes alternativas de respeito aos tratados internacionais, quando por especificidade da matéria, a envergadura do Direito Internacional não tutelava tal demanda jurídica. Nesse caso, Dupuy diagnosticou, assim como fez anteriormente Phillip Jessup, a emergência de uma novo Direito que pudesse dar conta de novas demandas jurídicas às margens do Direito nacional e do Direito internacional.

(...)

Nesse contexto, modelos de soft law podem manifestarem-se como atos de organizações internacionais, atos corporativos, métodos para resolução de controvérsias, atos produzidos por Estados que não se enquadrem no modelo constitucional interno ou sob a forma de tratados, atos de caráter principiológicos, normas técnicas e afins, tipificando um rol exemplificativo de suas hipóteses de incidência." (STAFFEN, 2018. p. 76/78)
} 


\section{Ações internacionais para suprimir o tráfico de pessoas e armas e o Tratado de} Palermo no combate às organizações criminosas

A década de 90 do século XX foi marcada pela preocupação em relação à expansão e evolução das organizações criminosas, especialmente relacionadas ao tráfico de armas e pessoas. Do mesmo modo que o tráfico de drogas, essa prática criminosa foi incentivada e facilitada pelo desenvolvimento dos meios de transporte e comunicação, e pela impotência dos Estados diante do quadro de enfraquecimento da soberania num cenário de Transnacionalidade.

Segundo relatório de 2010 da UNODC (United Nations Office on Drugs and Crime) estimava-se que o tráfico de pessoas gere um ingresso anual de US\$ 3 bilhões na Europa, enquanto que o tráfico de migrantes da América Latina para os Estados Unidos geram US\$ 6,6 bilhões anuais (UNODC, 2010).

No Brasil, no ano de 2014 "as autoridades brasileiras relataram 44 vítimas de tráfico para fins de exploração sexual, 26 mulheres adultas e 18 crianças do sexo feminino. Em 2015 as autoridades relataram 101 vítimas traficadas para o mesmo fim, sendo 51 mulheres adultas e 50 crianças do sexo feminino. Com o mesmo objetivo em 2016, as autoridades relataram 75 vítimas, 33 mulheres adultas e 42 crianças do sexo feminino.” (UNODC, 2018).

No mesmo relatório há a informação de que o mercado mundial de armas de fogo ilícitas alcança a cifra de US\$ 170 a 320 milhões anuais. O relatório chegou à conclusão de que a criminalidade organizada transnacional está se tornando um grande centro de poder paralelo.

Nesse panorama ao final do século - em 15 de novembro de 2000 - foi aprovada a Convenção de Palermo (Convenção contra o Crime Organizado), nome pelo qual ficou conhecido o Tratado que tem por objetivo o combate ao crime organizado transnacional. Esse tratado teve especial relevância já que tipificou as atividades criminosas que são cometidas por grupos organizados, e que ultrapasse as fronteiras de mais de um país, conceituando que "grupo criminoso organizado" é um “[...] grupo estruturado de três ou mais pessoas, existente há algum tempo e atuando concertadamente com o propósito de cometer uma ou mais infrações graves ou enunciadas na presente Convenção, com a intenção de obter, direta ou 
indiretamente, um benefício econômico ou outro benefício material" (BRASIL, 2004). Foi incorporada no ordenamento jurídico brasileiro com a edição do Decreto 5.015 de março de 2004.

A cidade de Palermo, na Sicília, não foi escolhida por acaso. A região da Itália era alvo de atividades criminosas no sul do país, dos conhecidos mafiosos italianos, e era também o cenário da Operação Mãos Limpas, conhecido processo de grande importância na Itália que pretendia o combate a corrupção desencadeada após a denúncia de licitações fraudulentas.

O foco do referido Tratado é direcionado a várias atividades criminosas organizadas: tráfico de drogas, armas, pessoas, lavagem de dinheiro, tráfico de animais exóticos, lenocínio, homicídio, pedofilia, entre outros. O objetivo central é estabelecer uma cooperação entre os países signatários, que se comprometem a uma série de medidas sugeridas na convenção, como a tipificação de atividades criminosas, extradição, assistência jurídica mútua, cooperação policial, facilitação na investigação transnacional, além de transferência de conhecimento e tecnologia.

À Convenção de Palermo foram adicionados três protocolos para áreas distintas, a primeira para prevenir e suprimir o tráfico de pessoas, mulheres e crianças; o segundo contra contrabando de migrantes por terra, mar e ar - tipificando o crime de contrabando, mas prevendo a proteção do migrante contrabandeando; e o terceiro, contra a fabricação e tráfico ilícito de armas de fogo, suas peças, componentes e munições. Embora tratando de áreas diferenciadas, todas abordam a criminalidade transnacional e organizada voltada ao tráfico.

Do mesmo modo que ocorreu com a Convenção Contra o Tráfico Ilícito de Entorpecentes e Substâncias Psicotrópicas, os países signatários se comprometeram a adotar uma série de ações visando o combate ao crime organizado transnacional, entre eles tipificar atos relacionado a participação em grupos criminosos organizados, lavagem de dinheiro; permitir e facilitar atos de investigação e acautelamento, como extradição, cooperação policial, além de promover a capacitação de agentes de segurança.

Convenção de Palermo previu uma série de dispositivos com olhos no aperfeiçoamento das técnicas de combate à criminalidade transnacional, como a responsabilização das pessoas jurídicas nos âmbitos penal, civil e administrativo, aduzindo, ainda, que a responsabilização não obstará a persecução penal contra as pessoas físicas que tenham cometido as infrações. ( PEREIRA, 2016, p. 58) 
A constatação do caráter transnacional da criminalidade - grande mérito da Convenção de Palermo - fortaleceu a convicção de que as ações voltadas ao seu combate devem se dar no âmbito da cooperação entre os países, pois atividades isoladas não surtirão qualquer efeito prático.

\section{O combate internacional à corrupção, lavagem de dinheiro e o Tratado de Mérida}

O início do século XXI, por sua vez, foi marcado pela preocupação com a corrupção e a lavagem de dinheiro dela decorrente bem como oriunda de outros crimes, e em 31 de outubro de 2003 foi aprovada a Convenção das Nações Unidas contra a Corrupção (Tratado de Mérida). No Brasil a incorporação se deu através do decreto 5.687, de 31 de janeiro de 2006.

Esse tratado prevê que cada Estado signatário, obedecendo aos princípios fundamentais de seu ordenamento jurídico interno, fomentará políticas e medidas para o combate a corrupção, com técnicas de investigação como entrega vigiada, vigilância eletrônica ou de outras, também para evitar a prática de lavagem de dinheiro.

É certo que na Convenção contra o Tráfico de Drogas já havia sido pioneira, obrigando que os países signatários criminalizassem a lavagem de dinheiro oriunda do crime de tráfico de entorpecentes - hoje chamada de primeira geração. É que naquele momento a intenção principal era de combate específico ao tráfico de drogas, reconhecendo-se que o mecanismo mais eficiente seria através do bloqueio de ativos gerados por esse crime.

Por outro lado, na Convenção de Palermo houve uma evolução com a previsão no artigo 6 quanto à criminalização da lavagem do produto do crime e instituía medidas para seu combate, ampliando o rol de crimes antecedentes, o que foi chamada de segunda geração.

Já a Convenção de Mérida inaugura o que podemos chamar de terceira geração, já que no art. 23 prevê a possibilidade de reconhecer a lavagem de dinheiro qualquer que seja o delito precedente. Há também um aumento da Cooperação Jurídica Internacional, cooperação e auxílio direto e homologação e exequatur das decisões estrangeiras. $\mathrm{O}$ art. 57 prevê, por sua vez, que se tratando de erário, a recuperação internacional de ativos deve ser integral.

A Convenção de Mérida que tem o escopo específico de combate a corrupção nos mais diferentes níveis, apresentou pontos determinantes no combate à lavagem de dinheiro, 
prevendo a necessidade de cooperação internacional para a investigação, regulamentação e fiscalização administrativa das instituições financeiras, intensificação da fiscalização dos valores transferidos além fronteiras. Há uma recognição que a máxima "follow the money" é a forma mais eficaz de combate ao crime organizado.

Entre estas medidas, destaca-se a que determina que cada Estado estabelecerá um amplo regimento interno de regulamentação e supervisão dos bancos e das instituições financeiras não bancárias, incluídas as pessoas físicas ou jurídicas que prestem serviços oficiais ou oficiosos de transferência de dinheiro ou valores, ou mesmo outros órgãos que sejam particularmente suspeitos de utilização para a lavagem de dinheiro. (PEREIRA, 2016, p. 51)

Assim, é possível perceber que os tratados internacionais foram no sentido de aprimorar e intensificar a cooperação internacional no que diz respeito a investigação e processamento das ações judiciais envolvendo a criminalidade transnacional.

O enfoque no crime de lavagem de dinheiro é o fortalecimento da convicção de que as organizações criminosas, tornando-se centros de poder e movimentando cifras bilionárias, só poderiam ser minadas atacando-se a movimentação financeira e a tentativa de "branquear" esses valores. A esse respeito é importante relembrar a origem da expressão. É que sendo os valores produtos de atividade criminosa, são eles considerados "sujos". Por conta disso, há a intenção dos criminosos de "branquear" ou "lavar", dando a aparência de que seriam fruto de atividade lícita.

As autoridades policiais e criminais passaram a perceber a necessidade de investigar a origem dos ativos financeiros, para alcançar as atividades criminosas. Por conta disso, a persecução voltada às atividades financeiras dá a diretriz das determinações aos Estados signatários, especialmente no que diz respeito às instituições financeiras e outras empresas e atividades que trabalham com bens de alto valor financeiro.

Interessante referência a esse assunto foi o entendimento do STF - especialmente no “Caso Mensalão" (Ação Penal 470) - que entendeu por afastar a Convenção de Palermo e não aceitou a acusação pelo crime de lavagem de dinheiro tendo como delito antecedente a participação em organizações criminosas, quando as condutas foram praticadas antes da 
edição da lei que tipificou a prática criminosa (Lei 12.850/2013). Na época, o relator entendeu que não era possível suprir a inexistência de lei penal incluindo norma de natureza incriminadora, apenas com a invocação da Convenção Internacional de Palermo, ainda que ela tenha sido incorporada ao ordenamento jurídico brasileiro pelo Decreto 5.015/2004.

\section{A anomia no âmbito internacional quanto à institucionalização de uma cooperação jurídica internacional para evitar a prática de crimes ambientais transnacionais}

Não há dúvidas de que uma ou a maior preocupação mundial atualmente diz respeito à proteção ambiental, embora também se alie à essa, a inquietude em relação aos crimes cibernéticos, biotecnologia, terrorismo, entre outros.

A apreensão com a intensa degradação do meio ambiente e a necessidade de desenvolvimento de mecanismos de proteção ambiental justificou uma maior inquietação com as formas legais para a proteção do meio ambiente. Não há dúvidas de que a questão ambiental é aquela que tem maior característica transnacional, já que o dano ambiental não obedece a fronteiras físicas. Desastres ambientais podem causar colapso além dos limites territoriais de um país, e várias controvérsias entre Estados podem surgir com base nesta questão.

Nesse cenário, intensificaram-se os esforços para que sejam aprovadas regras de proteção ao meio ambiente de forma globalizada. Com o intuito de promover a proteção ambiental de forma globalizada, as Nações Unidas possuem uma agência específica - ONU Meio Ambiente "responsável por promover a conversação do meio ambiente e o uso eficiente de recursos no contexto do desenvolvimento sustentável" (ONU, 2018), que cria recomendações para todo o planeta com a finalidade de "melhorar a qualidade de vida da população sem comprometer os recursos e serviços ambientais das gerações futuras" (ONU, 2018).

O meio ambiente surge como argumento nas controvérsias internacionais juntamente com os tratados sobre a matéria que normatizaram a proteção e o respeito ao meio ambiente. Significa afirmar que tais 
controvérsias são contemporâneas partindo do Século 20, quando os Estados começam a se reunir e firmar os tratados pró meio ambiente. O meio ambiente, contudo, poderia ter sido tema de controvérsias antigas que envolviam como argumento principal a delimitação de fronteiras e questões econômicas. Nessas controvérsias, porém, (...). A preservação ou o dano ao meio ambiente não eram argumentos relevantes a serem invocados numa controvérsia internacional, e muito menos importante era a preocupação com a saúde da população. (NOSCHANG, 2014, p. 295).

E nesse cenário, inúmeros são os tratados firmados entre nações independentes que se comprometem a implementar políticas públicas e leis mais rígidas para a proteção ambiental nos seus limites fronteiriços, com punições na área, cível, penal e administrativa.

Uma das formas mais decisivas de proteção ambiental é através do direito penal, "que tradicionalmente reacionava a posteriori contra um fato lesivo, individualmente considerado, se transforma agora em um Direito de gestão punitiva de riscos gerais." (SANTIAGO, 2015, p .78)

Santiago defende que se pode compreender que há um direito penal de risco, que "responde à escala de valores do grupo social que o mantém" e que seu âmbito são "os crimes ambientais, os crimes de risco catastrófico, como os relativos à energia nuclear ou estragos ocasionados por meios potencialmente destrutivos e relacionados às novas tecnologias, e delitos relativos à biotecnologia ou técnicas da vida, como os pertinentes à manipulação genética" (SANTIAGO, 2015, p. 79)

Ocorre que há vários exemplos mundiais de danos provenientes de crimes ambientais que transpassaram as fronteiras dos países, sendo seus efeitos pulverizados em várias partes do planeta, não se justificando que um crime ambiental seja responsabilidade exclusiva de apenas um Estado, devendo a proteção ambiental - nas mais diversas esferas, seja preventiva ou punitiva - superar a tradicional ideia de territorialismo e soberania e superar as fronteiras nacionais.

Um caso emblemático na questão ambiental é o do Equador x Colômbia quanto à pulverização de herbicidas tóxicos. Com a única preocupação de combater o tráfico de drogas na Colômbia, os EUA propuseram o Plano Colômbia, fornecendo herbicida glifosato produzido pela Monsanto para pulverizar o plantio de coca. Ocorre que essa pulverização 
atingiu outras plantações e culturas locais de subsistência da população, como mandioca, café, banana, feno, etc. Além disso, várias pessoas relataram casos graves de reações adversas na saúde. O caso foi levado a Corte Interamericana de Justiça que reconheceu a jurisdição com base na Convenção das Nações Unidas contra o Tráfico Ilícito de Entorpecentes e Substâncias Psicotrópicas, - já que não há nenhuma regulação internacional específica quanto aos danos de natureza ambiental - todavia o caso não foi julgado por conta de um pedido de arquivamento feito pela parte autora. (NOSCHANG, 2014, p. 306/311)

O Supremo Tribunal Federal já se debruçou quanto à questão do tráfico de animais silvestre de caráter transnacional para definir a competência da Justiça Federal nesses casos (STF, 2013). Contudo, nesse caso específico o tema é objeto da Convenção sobre Comércio Internacional das Espécies de Fauna e Flora Selvagens Ameaçadas de Extinção - CITES, restringindo-se apenas a esses casos e não a outros que eventualmente possam ter efeitos transnacionais.

Embora tenha ocorrido uma grande movimentação e aproximação das nações para a aprovação de tratados com a intenção de criar mecanismos de cooperação jurídica internacional para a prevenção e combate a crimes das mais diversas espécies (tráfico de drogas, pessoas, armas, lavagem de dinheiro, corrupção), não há qualquer intenção no que diz respeito aos crimes ambientais.

Os organismos e redes criados através dos tratados citados neste artigo se limitam embora de maneira engenhosa e eficiente - a persecução e investigação das práticas criminosas relatadas: tráfico de drogas, pessoas e armas e corrupção. Todavia, não se vê a utilização de todo este aparato de colaboração entre as nações para evitar a prática e punir aqueles que causam danos ao meio ambiente.

E nesse caso específico mais ainda seria necessária a utilização da cooperação jurídica internacional nos mais diversos níveis, já que por mais das vezes, esses danos e desastres ambientais são causados por sujeitos coletivos como grandes corporações transnacionais ou pelos próprios Estados, sendo ineficaz qualquer ação individual do Estado para seu enfrentamento.

Sem embargo, já houve a discussão para a criação de um Tribunal Internacional do Meio Ambiente, já que não há consonância entre os tratados já firmados quanto à existência de um órgão internacional com competência para julgamento de crimes ambientais transnacionais, especialmente praticado por corporações e pelos Estados. A ideia, contudo 
ainda não foi concretizada, e atualmente os Estados se limitam a uma responsabilidade individual na proteção ambiental, na forma do disposto no Princípio 11 da Eco-92:

Os Estados adotarão legislação ambiental eficaz. As normas ambientais, e os objetivos e as prioridades de gerenciamento deverão refletir o contexto ambiental e de meio ambiente a que se aplicam. As normas aplicadas por alguns países poderão ser inadequadas para outros, em particular para os países em desenvolvimento, acarretando custos econômicos e sociais injustificados.

No Brasil, há previsão legal de sanções penais pela degradação dos recursos naturais através da Lei 9.605/98 (Lei de Crimes Ambientais), que também inclui sanções de natureza civil e administrativa, além de regulamentar a previsão constitucional de responsabilização penal das pessoas jurídicas (art. 225, $\S 3^{\circ}$ ). Contudo, essa normativa obedece a uma tradição jurídica que prevê a observância ao princípio da territorialidade, de modo que só tem vigência sobre as práticas criminosas ocorridas no âmbito do território nacional.

O princípio 13 da Eco-92 também prevê a necessidade de cooperação entre os estados para a responsabilização por danos ambientais, mais ao contrário dos Tratados que já analisamos nesse artigo, não há um detalhamento quanto a cooperação jurídica internacional na investigação e punição dos autores, especialmente quando se diz respeito à responsabilização de pessoas coletivas. É que nada obstante se tenha expressamente sugerido que os países signatários fizessem a previsão em seus ordenamentos jurídicos para a responsabilização da pessoa jurídica, sabe-se que quando se trata da criminalidade transnacional e empresas de grande porte - empresas transnacionais - há necessidade de união de esforços e conhecimento técnico para que se possa realmente atingir o objetivo desejado.

Com efeito, há possibilidade de utilizar-se do Tratado de Mérida para a investigação da lavagem de dinheiro tendo por delito antecedente o crime ambiental, todavia, é possível perceber que todo o aparato de investigação financeira ainda se apoia em apurar outras atividades delituosas, sendo imperiosa a necessidade de um treinamento focalizado nas questões ambientais. 


\section{CONSIDERAÇÕES FINAIS}

A propagação da delinquência organizada foi estimulada também pelo processo de globalização que encurtou distâncias, facilitou a comunicação e proporciona fácil acesso a sofisticados meios tecnológicos. Nesta esteira, os Estados perceberam a necessidade de buscar meios efetivos contra o crime organizado, no combate da criminalidade organizada, conscientes de que não é possível se limitar a tratar da criminalidade apenas nos limites territoriais e soberanos dos países. Da mesma forma, o combate eficaz depende de cooperação entre as nações, com transferência de conhecimento e tecnologia e facilitação nos atos jurisdicionais de investigação e processamento.

$\mathrm{O}$ avanço nos tratados alusivos ao combate à criminalidade transnacional demonstra a percepção de que um dos meios mais eficientes para esse propósito é através do combate à lavagem de dinheiro e a fiscalização do sistema financeiro.

Contudo, embora os crimes de tráfico de drogas, pessoas e armas, além da corrupção, gerem efeitos danosos além das fronteiras nacionais, a sociedade global deve inquietar-se também com os danos ambientais transfronteiriços, especialmente praticados por grandes corporações e Estados, que tem consequências nefastas ao planeta. Nessa medida, ampliam-se os debates diante da complexidade que envolve a temática quanto à necessidade de uma cooperação jurídica internacional no enfrentamento do crime ambiental transnacional, e da punição dos atores internacionais envolvidos, através de um tribunal com competência exclusiva para a matéria.

Assim é que além de toda a preocupação e ações de políticas públicas para a proteção ambiental, deve haver uma integração entre as nações para o aumento da estrutura da cooperação jurídica internacional, para que esta possa alcançar também os delitos penais ambientais. Além disso, a criação de um Tribunal Penal Ambiental deve ser a prioridade nas discussões envolvendo o tema.

\section{REFERÊNCIAS DAS FONTES CITADAS}


BRASIL. Decreto 154, de 26 de junho de 1991. Promulga a Convenção Contra o Tráfico Ilícito de Entorpecentes e Substâncias Psicotrópicas. http://www.planalto.gov.br/ccivil_03/decreto/1990-1994/d0154.htm

.. Decreto 5.015, de 12 de março de 2004. Promulga a Convenção das Nações Unidas contra o Crime Organizado Transnacional.. Convenção de Palermo. http://www.planalto.gov.br/ccivil_03/_ato2004-2006/2004/decreto/d5015.htm

. Decreto 5.687, de 31 de janeiro de 2006. Promulga a Convenção das Nações Unidas contra a Corrupção, adotada pela Assembléia-Geral das Nações Unidas em 31 de outubro de 2003 e assinada pelo Brasil em 9 de dezembro de 2003. (Convenção de Mérida) http://www.planalto.gov.br/ccivil_03/_Ato2004-2006/2006/Decreto/D5687.htm

Lei 13.445 de 24 de maio de 2017. Institui a Lei de Migração. http://www.planalto.gov.br/ccivil_03/_ato2015-2018/2017/lei/113445.htm

CRUZ, Paulo Marcio \& OLIVIERO, Maurizio. Fundamentos do Direito Transnacional. In: Direito global: [recurso eletrônico] transnacionalidade e globalização jurídica. Itajaí: UNIV ALI, 2013

ECO-92. Declaração do Rio sobre Meio Ambiente e Desenvolvimento. http://www.meioambiente.pr.gov.br/arquivos/File/agenda21/Declaracao_Rio_Meio_Ambient e_Desenvolvimento.pdf Acesso em 01/09/2019

MESSA, ANA FlaViA. Curso de Direito Processual Penal. $2^{\text {a }}$ ed. São Paulo: Saraiva, 2014. Edição eletrônica

MOURA, Aline Beltrame. Os mecanismos de colaboração jurisdicional dos sistemas de solução de controvérsias da União Européia e do Mercosul. In: DAL RI JR, Arno \& MOURA, Aline Beltrame. Jurisdição Internacional: interação, fragmentação, obrigatoriedade. Ijuí: Ed. Unijuí, 2014

NOSCHAnG, Patrícia Grazziotin. A Proteção do Meio Ambiente na Corte Internacional de Justiça. In: DAL RI JR, Arno \& MOURA, Aline Beltrame. Jurisdição Internacional: interação, fragmentação, obrigatoriedade. Ijuí: Ed. Unijuí, 2014

PEREIRA, Emmanoel Campelo de Souza. Lavagem de dinheiro e crime organizado transnacional. São Paulo : LTr, 2016.

PRADO, Luiz Regis. Direito Penal do Ambiente. São Paulo: Editora Revista dos Tribunais, 2016.

SAntiago, Alex Fernandes. Fundamentos de Direito Penal Ambiental. Belo Horizonte: Del Rey, 2015. 
SILVA, Aline Beltrame. Os mecanismos de colaboração jurisdicional dos sistemas de solução de controvérsias da União Européia e do Mercosul. In: DAL RI JR, Arno \& MOURA, Aline Beltrame. Jurisdição Internacional: interação, fragmentação, obrigatoriedade. Ijuí: Ed. Unijuí, 2014.

STAFFEN, Marcio Ricardo. Interfaces do Direito Global. $2^{\text {a }}$ edição, ampliada e atualizada. Rio de Janeiro: Lumen Juris, 2018..

STELZER, Joana. O fenômeno da transnacionalização da dimensão jurídica. In: CRUZ, Paulo Marcio \& STELZER, Joana (org). Direito e Transnacionalidade. Curitiba: Juruá, 2011

STF. Recurso Extraordinário com Agravo. ARE 737977 RG, Relator: Min. LUIZ FUX, julgado em 02/05/2013, DJe-088.13-05-2013

UNODC A Globalização do Crime: Uma avaliação sobre a Ameaça do Crime Organizado Transnacional. https://www.unodc.org/documents/lpobrazil//noticias/2010/06/TOCTA_Report_2010_low_res.pdf Acesso em 05/08/2019

UNODC. Relatório Global sobre o Tráfico e Pessoas - Perfil de páis América do Sul $2018 . \quad$ https://www.unodc.org/documents/lpobrazil//Topics_TIP/Publicacoes/2018_GloTiP_South_America.pdf Acesso em 05/08/2019

VARELLA, Marcelo D. Direito Internacional Público. São Paulo: Saraiva Educação, 2018. 